\title{
Sustainable Innovation: An Adaptive Capabilities Approach to Understanding its Antecedents and Consequences: An Abstract
}

\author{
Kelly L. Weidner, Cheryl C. Nakata, and Zhen Zhu
}

\begin{abstract}
As firms are increasingly innovating to be more environmentally and socially responsible, academicians are highlighting how little we know in terms of the organizational capabilities required to develop such innovations. Additionally, very little is known about whether or not these innovations pay off for firms in the form of triple bottom-line rewards. Through the lens of stakeholder and marketbased capabilities theories, this study (1) examines the organizational capabilities that foster sustainable innovation, along with contingencies, as well as (2) its impact on the triple bottom line. This empirical study reveals that market-based sustainability and organizational unlearning positively impact sustainable innovation. Additionally, we examine a firm's status as a publicly owned firm as moderating the relationship between market-based sustainability and sustainable innovation, while we also examine organizational learning as interacting with unlearning to influence sustainable innovation. Finally, we find a complicated and interconnected relationship between the three dimensions of the triple bottom line: environmental performance, social performance, and economic performance. For managers, our study provides guidance on how to develop sustainable innovations and the expected benefits from this activity. For academicians, our research advances our understanding of the organizational antecedents, contingencies, and consequences of sustainable innovation.
\end{abstract}

References Available Upon Request

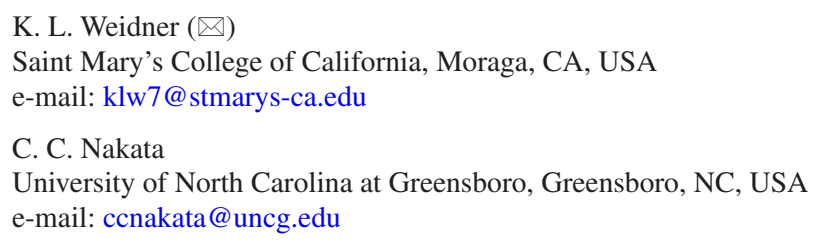

Z. Zhu

Suffolk University, Boston, MA, USA

e-mail: zzhu@suffolk.edu 